\title{
THE THERMO-HYGROMETRIC INDEX ON THE TERRITORY OF THE SOUTHERN DOBROGEA PLATEAU - A COMPONENT OF THE BALNEOCLIMATERIC TREATMENT
}

\author{
Grigore Elena ${ }^{1}$, Constantin (Oprea) Dana Maria ${ }^{1}$, Bogan Elena ${ }^{1}$, \\ Cristea Marius-Alin ${ }^{2}$, Tatu Florina ${ }^{1}$
}

Key words: air temperature, air humidity, bioclimatic factor, human body, balneoclimateric component, adaptation.

\begin{abstract}
The appearance of the analysis models, as a physical or mathematic form, has allowed simplifying the graphic representation of the processes specific to bioclimatology. Thus, the bioclimatic index becomes a useful and practical work tool in the scientific research, avoiding a multiple range of possible evaluations of the positive or negative potential that the climate of a region has on the human health. The proposed study analyzes the calculated values of the thermo-hygrometric index, for the period between the years 1981-2010. The database was improved with the meteorological data obtained from the five weather stations located in the Southern part of the Dobrogea Plateau. The mathematic formula launched by Kyle W.J. is based on the measured values of the air temperature $\left({ }^{\circ} \mathrm{C}\right)$ and relative air humidity $(\%)$. The obtained results allow to highlight both the specific bioclimatic areas and the way in which the tourism in the area can be affected. The bioclimatic extension and intensity is rendered by a suggestive and synthetic graphic expression. The maps showing the spatial distribution of the index were obtained by combining the isotherm method with the kriging interpolation specific to the ArcMap.
\end{abstract}

\section{INTRODUCTION}

The health status of the population according to the scientific research of the last 20 years represents, in fact, a state of the physical, mental and social wellbeing and not just a simple absence of a disease or an infirmity (WHO, 2019). Biometeorology is regarded as the science that studies the relationship between the atmosphere and the biosphere, highlighting, first of all, the importance

\footnotetext{
${ }^{1}$ University of Bucharest, Faculty of Geography; Corresponding author: ela_zigzag@hotmail.com

${ }^{2}$ Private medical office, Bucharest
} 
of the system for the human health (WHO, ISB, 2019). During life, the human body is permanently exposed to various environmental conditions and fluctuations of the meteorological elements manifestations, developing a series of problems related to stress. Also, all the scientific evidence from the last 20 years indicates that the climate change can also be associated with the negative results on human health (Patz et al., 2014).

In general, the modern scientific research aims to deepen the operating mechanism and the manifestation of the climate and bioclimatic systems. To support this assertion, there are a series of deeply quantitative information, highlighted and exposed to the general public, through the international studies, such as those launched by Beçancenot-1978, Höppe-1984, Mieczkowski-1985, Jendritzky-1991, Taesler-1991, Kyle-1994, Perry-1997, Becker-1998, McGregor, Nievwolt-1998, etc., as well as the national ones elaborated by Ionac-1999, Apostol-2004, Croitoru-2012, Teodoreanu-2013 etc.

The proposed studies present a series of reasons that print the usefulness of the evaluation process, but also that of highlighting an optimal condition in which the human body can function normally and its daily activity is not affected.

The analysis of the bio-meteorological indices is useful in highlighting the areas and periods of comfort or bioclimatic risk to which people in a region are exposed at a given time. The studies generally cover both the spatial and time variation of the analyzed indices. Also, it should not be ignored that the bioclimatic factors are not entirely to blame for the human comfort (science.gov).

There must be analyzed the individual reactions to heat exchange, as well as the subjective factors, which require the individual manifestation states. Thus, the bio-meteorological assessments have become a necessity (Howard, 1995), because any change that has occurred in the evolution of these systems affects both the components and the relationships between them, highlighting the influence of the weather conditions on the humans and their activity, either economic or recreational (Patz et al., 2014).

From this point of view, the present study aims, by analyzing the regime and the spatial distribution of the thermo-hygrometric index, to outline the areas of comfort or bioclimatic risk throughout the territory located in the Southern part of the Dobrogea Plateau. The information on the intensity level, as well as the degree of the spatial extension is useful in elaborating the strategies for evaluating the climatic-tourist potential of the analyzed region. This relational system has been proposed aiming to provide an accurate picture of the potential extension of the climate benefits on the human health, and in particular, to highlight the restrictive bioclimatic elements that may prevent the human efficiency. 


\section{INPUT DATA AND METHODS}

The study of the bioclimatic variables allowed the classification of the indices in the category of practical work tools. In general, the identification of factors and variables allows the evaluation to be carried out and highlight the positive or negative potential developed by the local climatic conditions, but also the way in which they influence the health of the population.

The thermo-hygrometric index expresses the actual effective ambient temperature perceived by the human body (Kyle, 1994, Ionac et al., 2008), a combined effect of the air temperature and humidity. The index is calculated irrespective of the values of the climatic characteristics, and the absence of the applicability limit allows its application throughout the year, including the annual average values. The calculated value of the index is obtained on the basis of the mathematic formula launched in 1994 by W.J. Kyle. In the specialized literature, this index is perceived as an alternative variant of calculating the discomfort index of Thom.

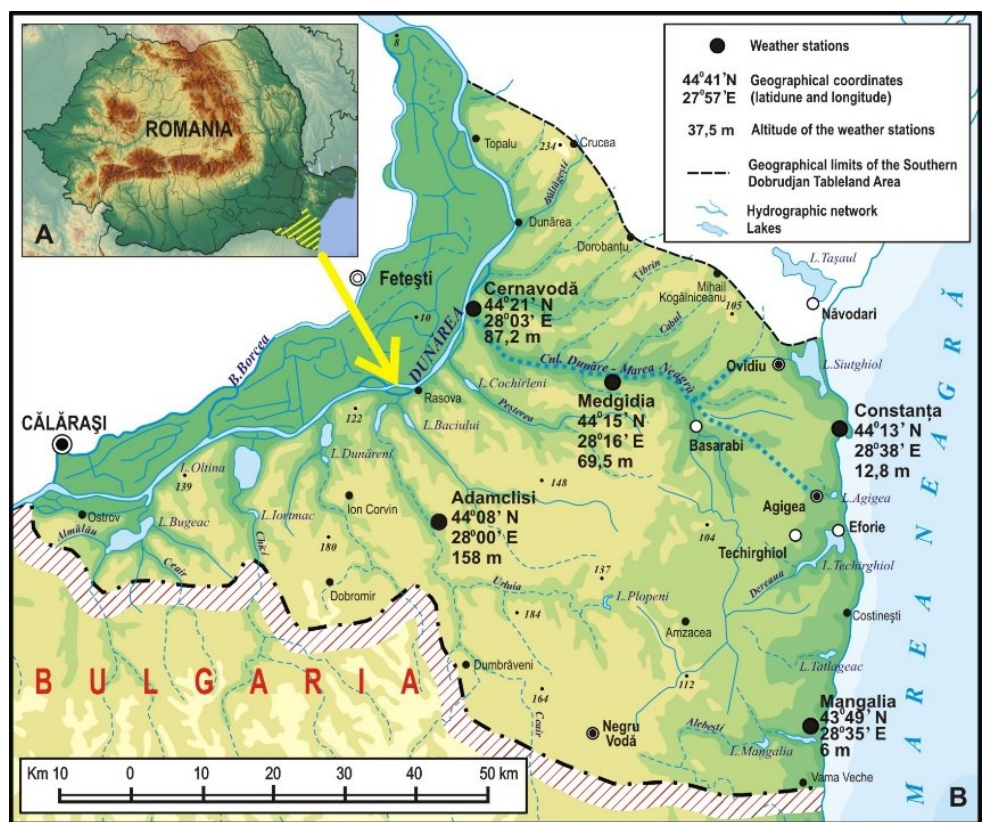

Fig.1. The geographic position of the Southern Dobrogea Plateau in Romania (a) and of the weather stations related to this space (b)

The Southern part of the Dobrogea Plateau located in the South-Eastern part of Romania is a land with many geographical contrasts. The plateau is known as a relief unit suspended between several relief units, with an area of 5,335 sqm 
(47.8\%) of the total area of the Dobrogea Plateau (Figure 1 a). The present study links the geographic information (Hastings et al., 1999 ) with the climatological data (New et al., 2002). The analysis was based on the existence of the meteorological database referring to the monthly average air temperatures and relative humidity, for the period 1981-2010, information from the weather stations: Cernavodă, Medgidia, Adamclisi, Constanţa and Mangalia (Figure 1 b).

Based on these monthly average meteorological data, the thermo-hygrometric index was calculated, and based on the specific limits of applicability, it was possible to identify areas of risk or of bioclimatic comfort: bioclimatic discomfort due to overcooling: $-20^{\circ} \mathrm{C} \ldots \leq+15^{\circ} \mathrm{C}$ (bioclimatic type: excessive cold, very cold, cold, cool); bioclimatic comfort : $+15^{\circ} \mathrm{C} \ldots \leq+20^{\circ} \mathrm{C}$ (bioclimatic type: comfortable); bioclimatic discomfort by heating: $+20^{\circ} \mathrm{C} \ldots>+30^{\circ} \mathrm{C}$ (bioclimatic type: hot, very hot, sultriness).

In general, the bioclimatic indices are calculated with the help of electronic computer programs based on the introduction of mathematic reference formulas for each bioclimatic parameter (Bucerzan et al., 2006). The present analysis aims to offer a suggestive image through the graphic and cartographic representations on the thermo-hygrometric index, both from the point of view of the evolution over a period and the size of the bioclimatic comfort and/or discomfort area in the Southern part of the Dobrogea Plateau. The bioclimatic map was obtained by combining the isotherm method with the kriging interpolation specific to the ArcMap.

\section{RESULTS AND DISCUSSIONS}

Irrespective the environmental conditions, the state of the bioclimatic comfort or discomfort is subjectively perceived by the human body. The analysis of the biometeorological and/or bioclimatic indices have the role of highlighting the influence of the climate on the human health. The influence can be seen as an individual action of the climatic characteristics - air temperature, air humidity, wind etc. (Frich et al., 2002, Sen Roy et al., 2004, El Kenawy et al., 2011, Croitoru et al., 2012) or as a synergistic action, arising from the combined action of at least two climatic characteristics.

The functional balance of the human body is disturbed by the external conditions. In order to maintain a proper homeostasis of the organism, there is involved its permanent effort to adapt to the environmental conditions (eea.europa.eu). The changes in frequency, duration and intensity in the manifestation of the meteorological events have, in most cases, negatively affected the human health, regardless of the type of activity performed by humans. Taking into account the optimal values of the effective temperature of the human body (respectively $15^{\circ} \mathrm{C}-20^{\circ} \mathrm{C}$; values indicating the discomfort due to hypothermia and 
hyperthermia, if they register values below or above this physiological limit), the optimal way of expressing the physiological sensations of the caloric states and the results obtained and following the application of the mathematic formula for the analyzed index, there were identified several value thresholds and areas of the bioclimatic comfort/discomfort specific to any physical point and time of the year. The variation of the thresholds depends both on the manifestation of the radiative and dynamic climatic factors and as well as on the presence of the local physical-geographical factors, with an essential role in the diversification of the climatic conditions and of the bioclimatic variables.

At the level of the analyzed plateau, the annual regime of the thermohygrometric index reflects the influence of the air temperature regime and the relative air humidity, but also their action that can be conjugated or opposable. This relational system can cause an amplification or diminution of the sensations of comfort or discomfort (either by heating or by cooling) felt by the human body, at different months of the year. The values obtained by applying the mathematic calculation formula have been represented cartographically (Figure 2) and centralized graphically (Table 2) for a better understanding and warning of the reader.

Tab.2. The annual regime of the thermo-hygrometric index $\left({ }^{\circ} \mathrm{C}\right)$ on the territory of the Southern Dobrogea Plateau (1981 - 2010)

\begin{tabular}{|c|c|c|c|c|c|c|c|}
\hline & mouth & & WEA & HER STA & ONS & & Annual \\
\hline & moutu & Cernavoda & Adamclisi & Medgidia & Constanța & Mangalia & mean \\
\hline & I & 0,48 & 0,46 & 0,66 & 2,38 & 2,61 & 1,31 \\
\hline & II & 2,51 & 1,65 & 1,99 & 3,01 & 3,28 & 2,48 \\
\hline & III & 6,01 & 5,34 & 5,51 & 5,68 & 5,79 & 5,66 \\
\hline & IV & 11,29 & 10,67 & 10,89 & 10,51 & 10,32 & 10,73 \\
\hline 1981 & $\mathbf{V}$ & 15,91 & 15,65 & 15,82 & 15,58 & 14,99 & 15,59 \\
\hline- & VI & 19,70 & 19,05 & 19,31 & 19,49 & 19,35 & 19,38 \\
\hline & VII & 22,49 & 21,58 & 21,80 & 21,38 & 20,99 & 21,64 \\
\hline & VIII & 20,90 & 19,99 & 20,09 & 21,12 & 20,94 & 20,60 \\
\hline & IX & 16,73 & 16,59 & 16,62 & 17,79 & 17,60 & 17,06 \\
\hline & $\mathbf{X}$ & 11,87 & 11,70 & 11,85 & 13,25 & 13,19 & 12,37 \\
\hline & XI & 6,25 & 5,99 & 6,39 & 7,88 & 8,04 & 6,91 \\
\hline & XII & 1,65 & 2,31 & 2,28 & 4,14 & 4,31 & 2,93 \\
\hline Annu & mean & 11,31 & 10,91 & 11,10 & 11,85 & 11,78 & 11,39 \\
\hline
\end{tabular}

The calculated values indicate that the territory of the Southern Dobrogea Plateau is in the cold bioclimatic area, with an average value of $11.39^{\circ} \mathrm{C}$. Regarding the average annual values of the index, it can be noticed a variation of $0.94^{\circ} \mathrm{C}$, from the West to the East of the territory. The average annual values were obtained when the annual average air temperature ranges from $+10.9^{\circ} \mathrm{C}$ to $+11.8^{\circ} \mathrm{C}$, and 


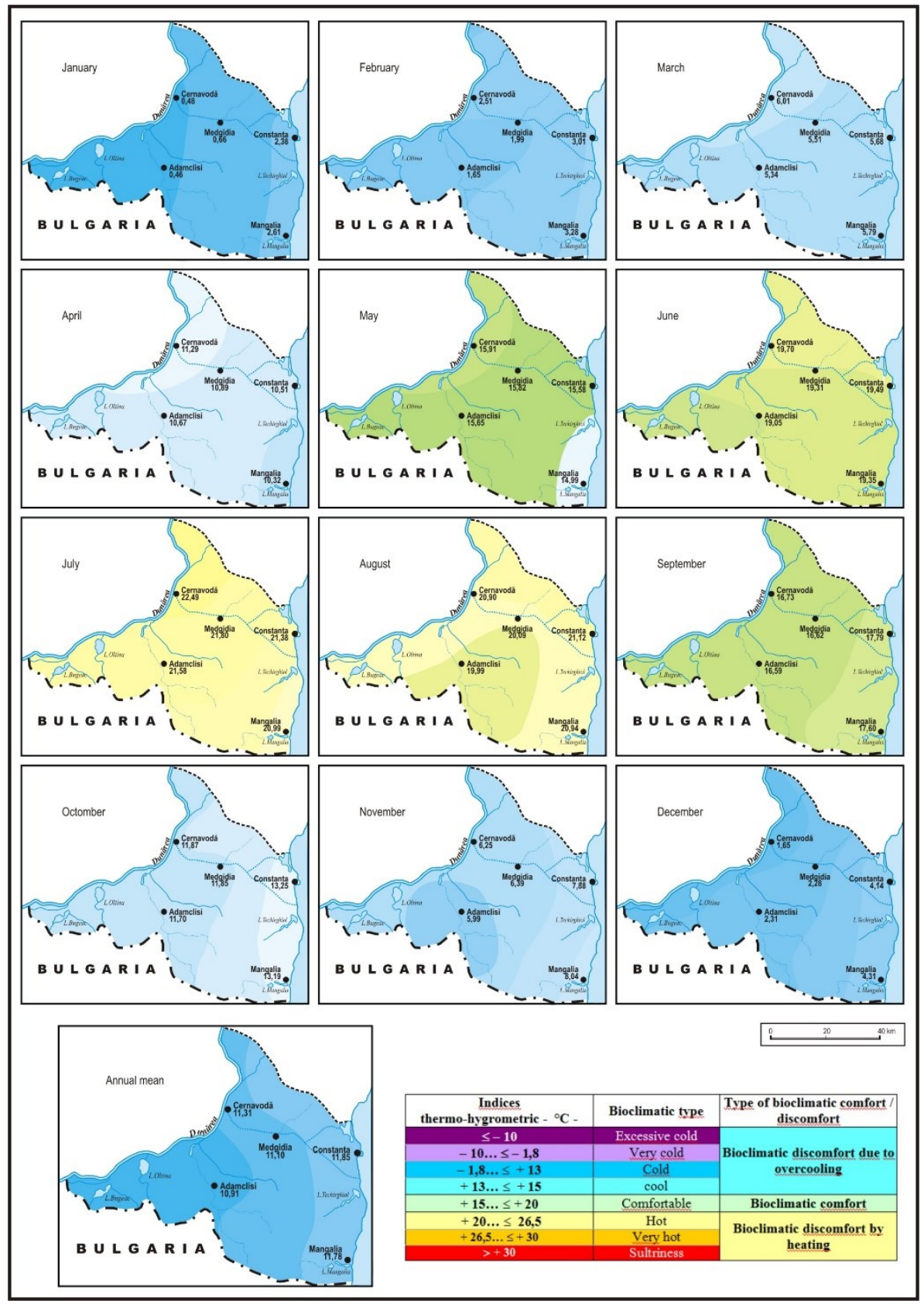

Fig.2. The distribution of the monthly average values of the thermo-hygrometric index on the territory of the Southern Dobrogea Plateau (1981 - 2010) 
those of the relative air humidity between $77.9 \%$ and $81.5 \%$. The lowest annual average value of the calculated index, of $10.9^{\circ} \mathrm{C}$, was recorded at Adamclisi and the highest, of $11.85^{\circ} \mathrm{C}$ at Constanta. The two observation points, from a geographical point of view, are found in the central-continental part and, respectively, in the East of the analyzed area, on the Black Sea shore. For example, in the period between November and February, the index values are low in the West and increased in the East of the plateau. The situation changes during the rest of the months, when the index registers lower values in the East of the plateau compared to the rest of the analyzed territory.

Analyzing the monthly variation, it can be said that the cold bioclimatic regime is installed from October to April, except for the coastal area. For example, in October, at the Black Sea shores, the index shows values above $13.0^{\circ} \mathrm{C}$, framing the area during the cold and not the frigid period. The bioclimatic comfort is recorded in May, June and September, with values ranging from $15.58^{\circ} \mathrm{C}$ (Constanta) to $19.99^{\circ} \mathrm{C}$ (Adamclisi). An exception is in Mangalia area, in May, with a cold bioclimate, with a slight attenuation, respectively a cool bioclimatic discomfort, because of an air temperature of $+15.0^{\circ} \mathrm{C}$ and a relative humidity of $81.1 \%$. The index values above $20.0^{\circ} \mathrm{C}$ specific for July and August, frame the analyzed territory in the hot bioclimatic area, highlighting the potential of bioclimatic risk through heating. In this situation, both the population of the region and the tourists feel a bioclimatic stress smoothed due to the heat. In the Adamclisi area, in August, a bioclimatic comfort is installed (the air temperature being of + $21.1^{\circ} \mathrm{C}$ and the air relative humidity of $71.9 \%$ ).

The annual average values indicate that the entire plateau maintains a cool bioclimate, so that the human body is subjected to a greater caloric adaptation effort. The value variation of the index is due to the air temperature which shows a positive difference of over $+20.0^{\circ} \mathrm{C}$, but also the relative air humidity by $22.2 \%$. The variations of these climatic parameters occur regardless of altitude and area, if they are closer or farther from the bordering aquatic surfaces, such as the Danube, the Danube - Black Sea channel, the fluvial or maritime firths and the Black Sea. The bioclimatic stress manifested by cooling or heating is predominantly felt by the elderly people and children, depending on their nutritional status and health, the level of training of the body that becomes sensitive in case of exposure to cold or heat, regardless of the activity supported at one point.

By revealing the values of the thermo-hygrometric index, of their monthly distribution, of the actual physiological sensations felt, there was obtained the information indicating the visible differences of comfort from one place to another and the existence of a favorable bioclimate to the Eastern part of the studied area. For example, the long and pleasant autumn, felt as a cold and humid spring, shows an optimum bioclimate, considered as an important factor and with a 
significant influence during the spa treatment. Also, the values that indicate the installation of the bioclimatic comfort (present since May in the studied area), in turn, becomes an essential component in the analysis of the spa conditions and respectively, in evaluating the potential of the therapeutic effect. Thus, it can be noticed that the comfort felt by the human body depends directly on the weather and local climatic conditions. The continuous spatial and temporal variation of the current state requires the permanent adaptation of all the integration and control physiological systems of the human body.

On the hot and humid summer days, for example, the body heat is lost by intensifying the processes of perspiration, and the evaporation of water from the skin surface is favoured and accentuated. In the studied area, during the hot season, the production and maintenance of a state of bioclimatic discomfort is due to the intensification of the tropical dry air from the South and South-West of Europe. Under these conditions, the risk of accumulation of an excess of metabolic heat is increased.

The danger of installing the hypo-caloric stress through hyperthermia is frequent in the months specific to the cold semester and diminished, with a slow manifestation, in the autumn months (the thermic comfort being present in October). The index regime towards the Romanian coastline shows a diminished cooling effect, due to the large amount of heat released by the sea water.

A greater attention should be paid to sudden variations (Patz et al., 2014), as it warns of the need to take measures regarding the food and clothing protection (Howard, 1995), in order to counteract the effects of hypothermia on the people which are exposed in an area at a certain time.

\section{CONCLUSIONS}

The obtained results show that the bioclimatic risk depends on the variation of the climatogenic factors, and the succession regime of the bio-meteorological influences is affected by the local climatic ones. Also, the effects of these biometeorological manifestations, which act on the whole human body, influence, in different ways, the recovery and healing of certain physiological conditions. The area analyzed by the bioclimatic characteristics allows the efficient use of the summer months for the helio-therapy procedures, and of the autumn ones for the aero-therapy procedures.

It should not be ignored that bio-meteorological information indicates that there are unfavourable periods for long-term outdoor activities because the long exposure negatively affects the human reactions and decreases the resistance to the influence of the environmental and biological risk factors. 
Furthermore, today, it does not seem to be a problem, but a continuous increase in the tendency of the bioclimatic stress will involve more complications of the population health. A spa treatment together with other factors specific to the life of a human society, becomes an important therapeutic agent in promoting the health of the population, increasing the active period of life and preventing many diseases that mark the evolution of the modern human society.

\section{References:}

1. Ciulache S., Torică V. (2007) Clima Dobrogei, Analele Universităţii din București, seria Geografie, Anul LII/2003

2. Croitoru Adina-Eliza, Sorocovschi V. (2012) Introducere in biometeorologia umană, Casa Cărţii de Ştiinţă, Cluj-Napoca.

3. Croitoru Adina-Eliza, Piticar A. (2013) Changes in daily extreme temperatures in the extra Carpathians regions of Romania, International Journal of Climatology, 33, p.1987-2001, doi: 10.1002/joc.3567.

4. Daget P. (1977) Le bioclimat Mediterraneen: Analyse des formes climatiques par le systeme d'Emberger, https://link.springer.com/article/10.1007/BF00054477

5. Frich P., Alexander L.V., Della-Marta P., Gleason B., Haylock M., Klein Tank A.M.G., Peterson T. (2002) Observed coherent changes in climatic extremes during the second half of the twentieth century. Climate Research, 19, p. 193-212 doi:10.3354/cr019193

6. Hastings D.A., Dunbar P.K., Elphingstone G.M., Bootz M., Murakami H., Maruyama H., Masaharu H., Holland P., Payne J., Bryant N.A., Logan T., Muller J.P., Schreier G., MacDonald J.S. (1999) The Global Land One-kilometer Base Elevation (GLOBE) Digital Elevation Model, Version 1.0. National Oceanic and Atmospheric Administration, National Geophysical Data Center, 325 Broadway, Boulder, Colorado 80303, U.S.A., Digital data base http://www.ngdc.noaa.gov/mgg/topo/globe.html

7. Hillman PE. (2009) Thermoregulatory physiology, In: DeShazer, JA (eds). Livestock energetics and thermal enviromental management. ASABE: Moscow, Idaho, USA, pp. 23-48. https://elibrary.asabe.org/abstract.asp?aid=28295

8. Howard J.C. (1995) General Climatology, Prentice Hall of India Ltd: New Delhi.

9. Ionac Nicoleta, Ciulache S. (2008) Atlasul bioclimatic al României, Editura Ars Docendi a Universităţii din Bucureşti, Bucuresti.

10 Kyle W.J., (1992), Summer and winter patterns of human thermal stress in Hong Kong, Kyle W.J. and Chang C.P. (eds.). Proc. Of the 2nd Int. Conference on East Asia and Western Pacific Meteorology and Climate, Hong Kong. World Scientific, Hong Kong, 557-583.

11. Lungu M., Panaitescu L., Nita S. (2011) Aridity, climatic risk phenomenon in Dobrudja, Present Environment and Sustainable Development 5 (1), p. 179-190.

12. Mackinder H.J. (1951) Seven lamps of geography, Geography Vol.36.

13. McGregor R., Nieuwolt S. (1998) Tropical Climatology, John Wiley and Sons Ltd: London.

14. New M., Lister D., Hulme M., Makin I. (2002) A high-resolution data set of surface climate over global land areas, Climate Research 21,1-25 doi:10.3354/cr021001 
15. Patz J.A., Frumkin H., Holloway T., Vimont D.J., Haines A. (2014) Climate change: challenges and opportunities for global health, Oct 15;312(15):1565-80. doi: $0.1001 /$ jama.2014.13186.

16. Parsons K. (2003) Human Thermal Environments, 2nd ed., Taylor and Francis, London.

17. Perry A., Perry Vivien (1986) Climate and Society, Bell \& Hymann, London.

18. Sen Roy, S., Balling R.C. Jr. (2004) Trends in Extreme Daily Precipitation Indices in India, International Journal of Climatology, 24, p. 457-466. DOI: 10.1002/joc.995.

19. Steadman R.G. (1979) The assessment of sultriness. Part I: A temperature-humidity index based on human physiology and clothing science. J. Applied Meteorol., Vol 18.

20. Thom E.C. (1959) The Discomfort Index. Weatherwise 12, 57-60.

21. Teodoreanu Elena, Dacos-Swoboda Mariana, Ardeleanu Camelia, Enache L. (1984) Bioclima staţiunilor balneoclimatice din România, Editura Sport-Turism, Bucureşti.

22. Teodoreanu Elena (2002), Bioclimatologie umană, Editura Academiei Române, Bucureşti

23. VDI (1998) Methods for the human-biometeorological assessment of climate and air hygiene for urban and regional planning. Part I: Climate. VDI guidline 3787. Beuth, Berlin

24. BS 7963 (2000) Guide to the assessment of heat strain in workers wearing personal protective equipment, BSI, London.

25. ISO 7730 (2005) Analytical determination and interpretation of thermal comfort using calculation of the PMV and PPD indices and local thermal confort criteria, Geneva: International Standards Organisation.

26. IPCC (2007) Climate Change: The Physical Science Basis, Contribution of Working Group I to the Fourth Assessment Report of the Intergovernmental Panel on Climate Change. Solomon, S., Qin, D., Manning, M., Chen, Z., Marquis, M., Averyt, K.B., Tignor, M., Miller, H.L. (eds). Cambridge University Press: Cambridge, United Kingdom and New York, NY, USA.

27. Proiectul European Climate Assessment \& Dataset (ECA\&D) Algorithm Theoretical Basis Document (ATBD) (2011) Royal Netherlands Meteorological Institute KNMI, http://eca.knmi.nl/documents/atbd.pdf

28. (2019) O.M.S, www.who.int

29. (2019) I.S.B, www.meteoetclimat.fr

30. (2019) https://pro.arcgis.com

31. www.science.gov

32. www.eea.europa.eu

33. www.biometeo.it

34. www.weather.gov

35. www.dwd.de

www.metoffice.gov.uk

www.noaa.gov

www.meteoromania.ro

2020 by the authors. Licensee UAIC, Iasi, Romania. This article is an open access article distributed under the terms and conditions of the Creative Commons Attribution (CC BY-NC-ND) license (https:// creativecommons.org/licenses/by-nc-nd/4.0). 